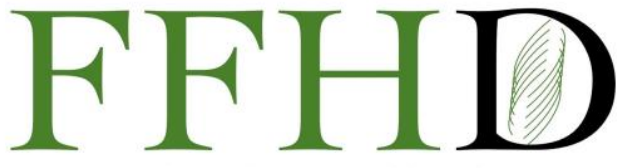

Functional Foods in Health and Disease

\title{
Effect of incorporating plant-based quercetin on physicochemical properties, consumer acceptability and sensory profiling of nutrition bars
}

\author{
Uma Bansal ${ }^{1}$, Aastha Bhardwaj ${ }^{1}$, Som Nath Singh ${ }^{2}$, Sucheta Khubber ${ }^{3}$, Nitya Sharma ${ }^{4}$, Vasudha \\ Bansal $5^{*}$
}

\begin{abstract}
${ }^{1}$ Department of Food Technology, Jamia Hamdard, New Delhi, India; ${ }^{2}$ DRDO-Defence Institute of Physiology and Allied Sciences (DIPAS), Timarpur, Delhi, India; ${ }^{3}$ Centre for Innovative and Applied Bioprocessing, Mohali, Punjab, India; ${ }^{4}$ Centre for Rural Development \& Technology, Indian Institute of Technology, New Delhi, India; ${ }^{5}$ Department of Foods and Nutrition, Government Home Science College, Chandigarh-160011, Affiliated to Panjab University, Chandigarh, India

*Corresponding Authors: Dr. Vasudha Bansal, Assistant Professor, Department of Foods \& Nutrition, Govt. Home Science College Chandigarh, India; Dr. Nitya Sharma, Post Doctorate Fellow, Centre for Rural Development \& Technology, Indian Institute of Technology, New Delhi, India
\end{abstract}

Submission Date: January $7^{\text {th }}, 2022$; Acceptance Date: February 28th, 2022; Publication Date: March $4^{\text {th }}, 2022$

Please cite this article as: Bansal U., Bhardwaj A., Singh S. N., Khubber S., Sharma N., Bansal V. Effect of incorporating plant-based quercetin on physicochemical properties, consumer acceptability and sensory profiling of nutrition bars. Functional Foods in Health and Disease; Volume 12(3): 116-127. DOI: 10.31989/ffhd.v12i3.888

\section{ABSTRACT}

Background: Plant-based quercetin is usually produced using fruit and vegetable waste and is sold in the market in powdered form. Since it is already used as a supplement in various foods, a study was conducted to develop calorie rich nutrition bars using plant-based quercetin that may serve as a promising functional snack with high antioxidant property for general consumption by teenagers, adults, athletes and sports persons. This study deals with the development of a novel nutrition bar by utilizing a plant by-product.

Methods: Plant based pure quercetin extract powder (98\% Premium grade) was procured from HerbaDiet, Arkure Health Care, Rohtak, Haryana (India). Other materials used were: quinoa (Chenopodium quinoa) (Pro nature Organic Foods Pvt. Ltd.); instant white oats (Kellogg's India Pvt. Ltd., New Delhi); canola oil (Jivo Wellness Pvt. Ltd.); jaggery (Village product industries); nuts- comprising almond, cashew, walnut, roasted \& salted pistachios (Happilo International Pvt. Ltd.).

Objective: The study was carried out in order to formulate calorie and nutrient rich bars for all age-groups with a prime focus on antioxidant-quercetin. 


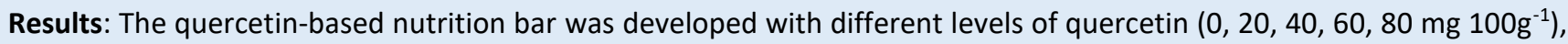
in addition to other ingredients including oats, quinoa, nuts, canola oil and jaggery. Addition of quercetin caused a significant $(p \leq 0.05)$ change in water activity, color and textural attributes of the bars. With the increase in the quercetin content, a significant decrease in the water activity and increase in the lightness $\left(\mathrm{L}^{*}\right)$ and hardness values of nutrition bar samples were observed. The quercetin enriched nutrition bars also had an increase in total phenolic content as well as antioxidant capacity, as assessed by DPPH radical scavenging activity. Evaluation of overall acceptability and sensory

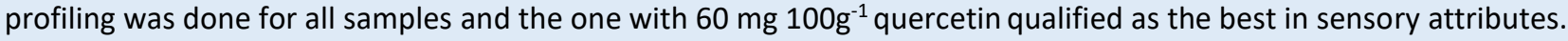

Conclusion: The results revealed that a quercetin-based nutrition bar can be a palatable and promising functional food with high antioxidant property.

Keywords: nutrition bar, quercetin, antioxidant activity, overall acceptability

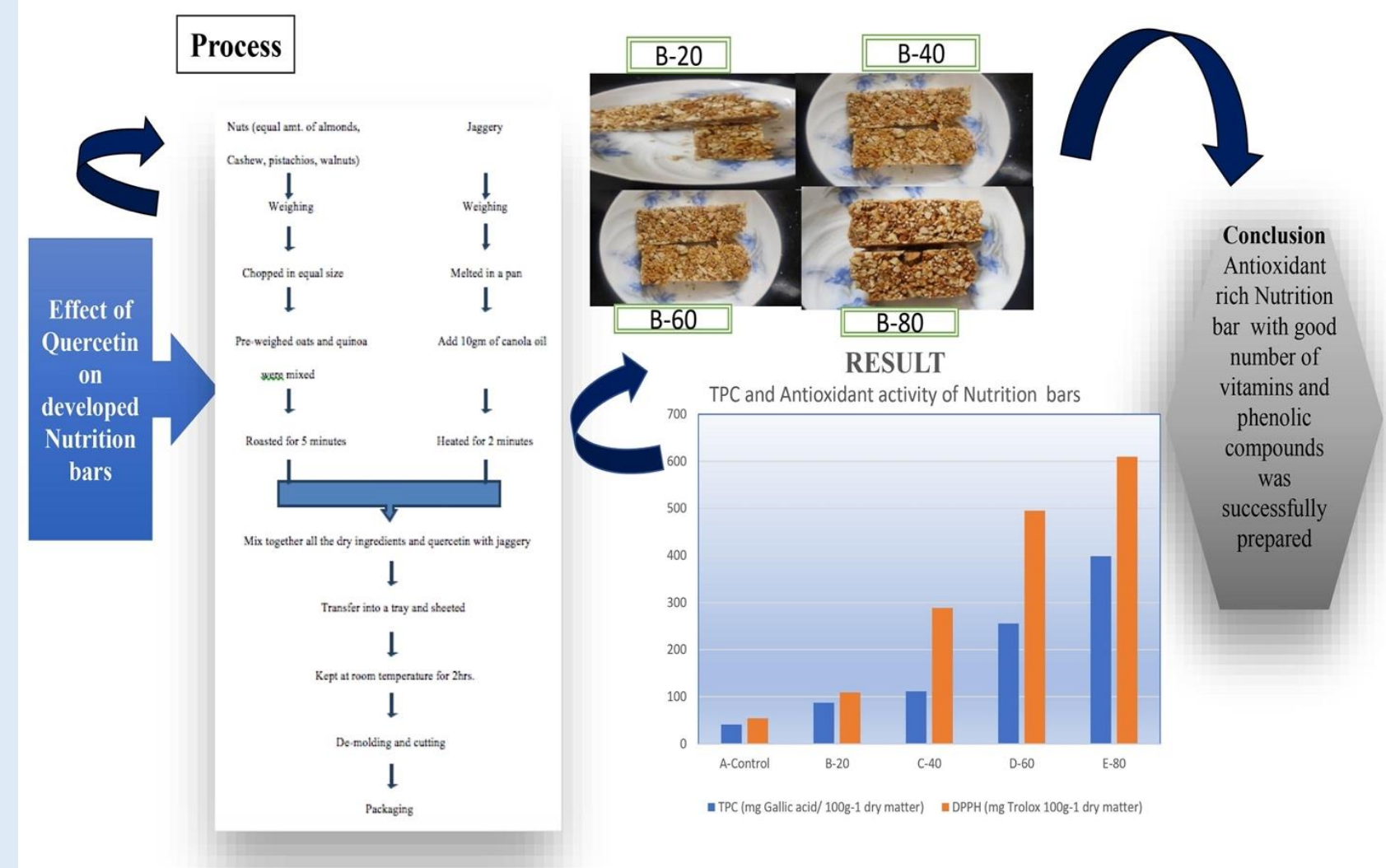

CFFC 2022. This is an Open Access article distributed under the terms of the Creative Commons Attribution 4.0 License (http://creativecommons.org/licenses/by/4.0)

\section{INTRODUCTION}

Quercetin is an abundant, plant-based phytochemical with potent antioxidant properties commonly found in onion, cherry, red wine, green tea, bark, olive oil, apple, blueberry, cranberry, nuts, buckwheat and broccoli [13]. The beneficial effects of quercetin is from its ability to function as an antioxidant by scavenging and neutralizing highly reactive species such as peroxynitrite and the hydroxyl radical, that may cause cellular damage [4-6]. Quercetin is commercially available in markets as a dietary supplement either in capsule or in powder form and is consumed for general health benefitting purposes. It has been estimated that an average person consumes approximately $10-100 \mathrm{mg}$ of 
quercetin daily through various food sources [7]. As per U.S. Food and Drug Administration (USFDA), up to 500 $\mathrm{mg} /$ serving of quercetin is generally recognized as safe (GRAS) for use as an ingredient in foods such as health beverages, processed fruits and fruit juices, cereal products, pastas, and soft candies (USFDA GRN no. 000341) [8]. Several research studies report that quercetin has a synergistic effect when combined with other flavonoid supplements, such as resveratrol, genistein, and catechins [9-11]. An interesting property of quercetin as a COVID-19 main protease inhibitor also has been demonstrated in a molecular docking study by Khaerunnisa et al. [12], however, further research is needed to further understand the potential use in the field of medicine.

Cereal-based nutrition bars have become one of the most prevalent ready-to-eat (RTE) foods among teenagers, adults, sportspersons, and athletes, owing to the high energy value as well as nutritional profile. Cereal based nutrition bars are formulated to create a product combining nutritional quality, long shelf life and ease of consumption, in order to either improve or substitute for a snack between meals or to complement meals [13]. Nutrition bars available in the present market are usually made up of cereals/pseudo-cereals such as oats, wheat or rice, and soy, along with dry fruits, honey, dates paste, corn syrup, sugar or jaggery and other miscellaneous ingredients that can be incorporated to enhance the nutritive value of bars. These key ingredients impart various functionalities to the nutrition bars by enriching them with phenolic compounds and vitamins that act as antioxidants, thus categorizing the bars as functional foods. Thus, in order to deliver bioactive compounds to the human system, such nutrition bars have proved to be a good food format.

Thus, the present study aims at the development and quality evaluation of an antioxidant rich cerealbased product in the form of a nutrition bar, with a locally available cheap source of nutrition, i.e., plant- based quercetin powder. Since quercetin powder is characterized by a typical bitter flavor, therefore, sensory acceptability among consumers is one of the key parameters that decides its commercial value and importance. Therefore, the study was conducted with sensorial attributes as dependent variables and quercetin content as an independent variable. To the best of author's knowledge, this is the first study that deals with development of a cereal based nutrition bar incorporating with quercetin in varying quantities. In the study, the antioxidant and sensory attributes were assessed.

\section{MATERIALS AND METHODS}

Materials: Plant based pure quercetin extract powder (98\% Premium grade) was procured from HerbaDiet, Arkure Health Care, Rohtak, Haryana (India). Other materials used were: quinoa (Chenopodium quinoa) (Pro nature Organic Foods Pvt. Ltd.); instant white oats (Kellogg's India Pvt. Ltd., New Delhi); canola oil (Jivo Wellness Pvt. Ltd.); jaggery (Village product industries); nuts- comprising almond, cashew, walnut, roasted \& salted pistachios (Happilo International Pvt. Ltd.).

Manufacturing of quercetin-based nutrition bar: Equal amounts of cashew, pistachios, walnuts, almonds were weighed ( $25 \mathrm{~g}$ ) and chopped in equal sizes. To develop a quercetin-based nutrition bar, white oats (20 g), quinoa $(10 \mathrm{~g})$ and nuts (25 g) were roasted for $5 \mathrm{~min}$ in a pan on low flame. Plant based quercetin extract powder was then added to the cereal-nut mixture in varying

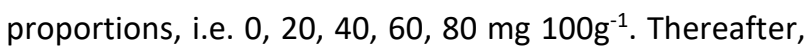
$40 \mathrm{~g}$ of jaggery was melted in another pan and mixed with $10 \mathrm{~mL}$ of canola oil. The mixture was heated for 2 minutes along with the cereal-nut mixture with varying proportions of quercetin powder. The composition was then transferred into trays of dimension $12 \times 10 \mathrm{~cm}$ and sheeted with the help of rolling pin. The trays were left at room temperature for $2 \mathrm{~h}$, de-moulded and cut such 
that the individual bars weighted $24 \mathrm{~g}$, approximately.

Table 1 shows the various ingredients and formulations of nutrition bars incorporated with different levels of quercetin. Each bar was then wrapped in butter paper, packaged in LDPE pouches and stored at room temperature, until further analysis. For sensory analysis, all nutrition bars were prepared on the same day and assessed within $24 \mathrm{~h}$. Figure 1 shows a basic flowchart for the preparation of quercetin-based nutrition bars.

Table 1. Formulation of nutrition bars with different levels of quercetin

\begin{tabular}{|c|c|c|c|c|c|}
\hline Ingredients (Part by weight) & A-Control & B-20 & C-40 & D-60 & E-80 \\
\hline Oats (g) & 30 & 30 & 30 & 30 & 30 \\
\hline Quinoa (g) & 10 & 10 & 10 & 10 & 10 \\
\hline Canola Oil (ml) & 5 & 5 & 5 & 5 & 5 \\
\hline Nuts- pistachio, almond, cashew, walnut (g) & 25 & 25 & 25 & 25 & 25 \\
\hline Jaggery (g) & 40 & 40 & 40 & 40 & 40 \\
\hline Quercetin (mg) & - & 20 & 40 & 60 & 80 \\
\hline
\end{tabular}

Figure 1. Flowchart for the manufacture of quercetin-based nutrition bar

Uniformly chopped nuts (equal amounts of almonds, cashew, pistachios, walnuts) and pre-weighed oats and quinoa were mixed

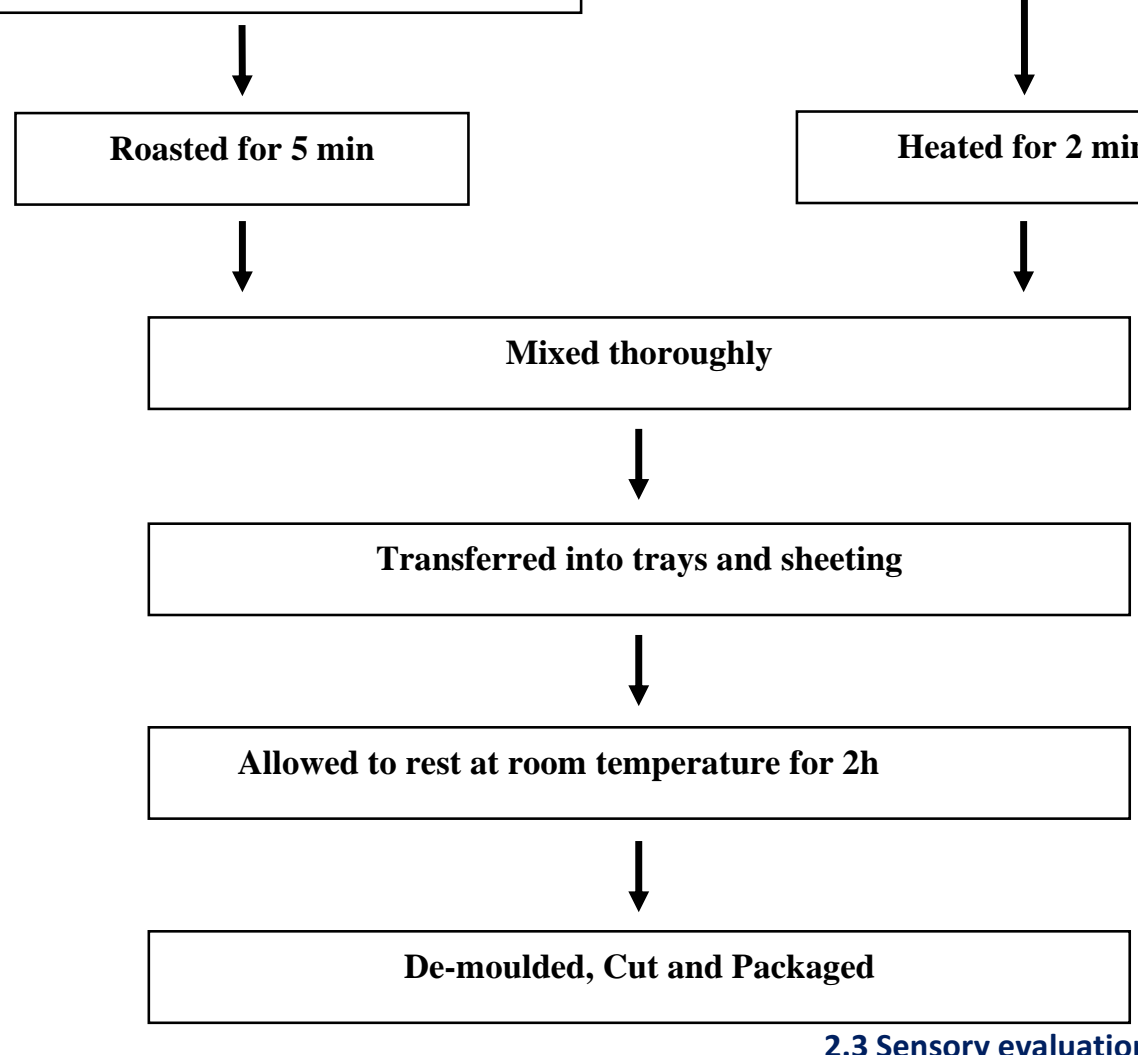

Pre-weighed melted jaggery and $5 \mathrm{~g}$ canola oil were mixed

Quercetin Addition 
Sensory panel: To compose a sensory panel, 30 regular consumers nutrition bars with a willingness to try a new composition were selected, in an age group of 20 to 45 years. The demography of consumers and their degree of fondness and frequency of consumption of nutrition bars (as 1- "Quite frequently", 2- "Once a week", 3"Once a month" and 4- "Once in six months") was enquired through a questionnaire. The selected panelists (with ' 1 ' and ' 2 ' frequency level) were explained the nature of the experiment and were asked to carry out the sensory evaluation in an isolated environment with proper lighting at room temperatures. The consumers were instructed to neutralize and clean their palate using warm filtered water before and in between each sample tasting.

\section{Overall favorability and food action rating scale: To} access the overall product favorability, a method similar to the one described by Ribeiro et al. [14] was followed. The quercetin-based nutrition bars were prepared on the same day and assessed within $24 \mathrm{~h}$ of preparation. Different samples of nutrition bars with dimensions of $12 \times 10 \mathrm{~cm}$, were coded with three-digit random numbers and were presented in a balanced monadic sequential order, to avoid any carry-over effects. Overall favorability of the nutrition bars was evaluated based on the appearance and texture, taste and flavor, aroma, and overall acceptability on a five-point scale (1 represented "dislike extremely"; 3 being "indifferent"; and 5 represented "like extremely"), and the overall favorability was taken as a mean of respective values. Further, a Food Action Rating Scale - FACT (willingness to eat the product if it was available on the market) was also evaluated using a five-point scale (1 represented "Would certainly not eat"; followed by 3 being "Unsure"; and 5 represented "Would certainly eat").
CATA (check-all-that-apply): The sensory panelists were presented a set of CATA ballot with a list of sensory descriptors that appropriately defined the nutrition bars [15]. Before evaluating the samples, since the selected sensory panel was a regular consumer of nutrition bars (section 2.4.1), they were asked to write down the at least six descriptors that could be associated with similar cereal compositions like cereal bars with sugar, honey, peanuts, flakes, dry fruits, etc. Common descriptors were then randomly selected from the list given by the sensory panel and a CATA ballot with 14 descriptors was finally developed under three modalities - appearance, taste and flavor, and mouthfeel (Figure 2). To further characterize the nutrition bar samples, these 14 descriptors were divided into 7 positive and 7 negative attributes (as indicated in Figure 2).

\section{Physicochemical properties}

Moisture content and water activity: The moisture content of the formulated nutrition bar samples was evaluated using the AOAC international method [16]. While the water activity was measured using a thermoconstanter (Novasina, Lachen, Switzerland).

Texture analysis: The hardness, springiness, cohesiveness, resilience and chewiness of the formulated nutrition bar was measured using a Texture analyzer (TA-XT2i, Stable Micro System Ltd., Surrey, UK), with a $25 \mathrm{Kg}$ load cell and the application program supplied with the equipment (Texture Expert for Windows, version 1.19). Samples of the formulated nutrition bar were cut in a shape of block with dimensions: $2 \mathrm{~cm}$ length $\times 2 \mathrm{~cm}$ width $\times 1 \mathrm{~cm}$ height. The blocks were pierced using a HDP/BSK stainless steel blade with the following set condition: $2.0 \mathrm{~mm} / \mathrm{s}$ pretest speed, $2.0 \mathrm{~mm} / \mathrm{s}$ test speed, and $2.0 \mathrm{~mm} / \mathrm{s}$ post-test speed. 
Instrumental color analysis: Instrumental color analysis of the formulated nutrition bars was done by determining the $L^{*}, a^{*}$ and $b^{*}$ values using a colorimeter (Model CM-5, Minolta, Osaka, Japan). L* (lightness), a* (redness) and $b^{*}$ (yellowness) readings were based on the CIELab system, with the following characteristics: $30.0 \mathrm{~mm}$ measurement area, $10^{\circ}$ angle of view, illuminant D65 with specular component included.
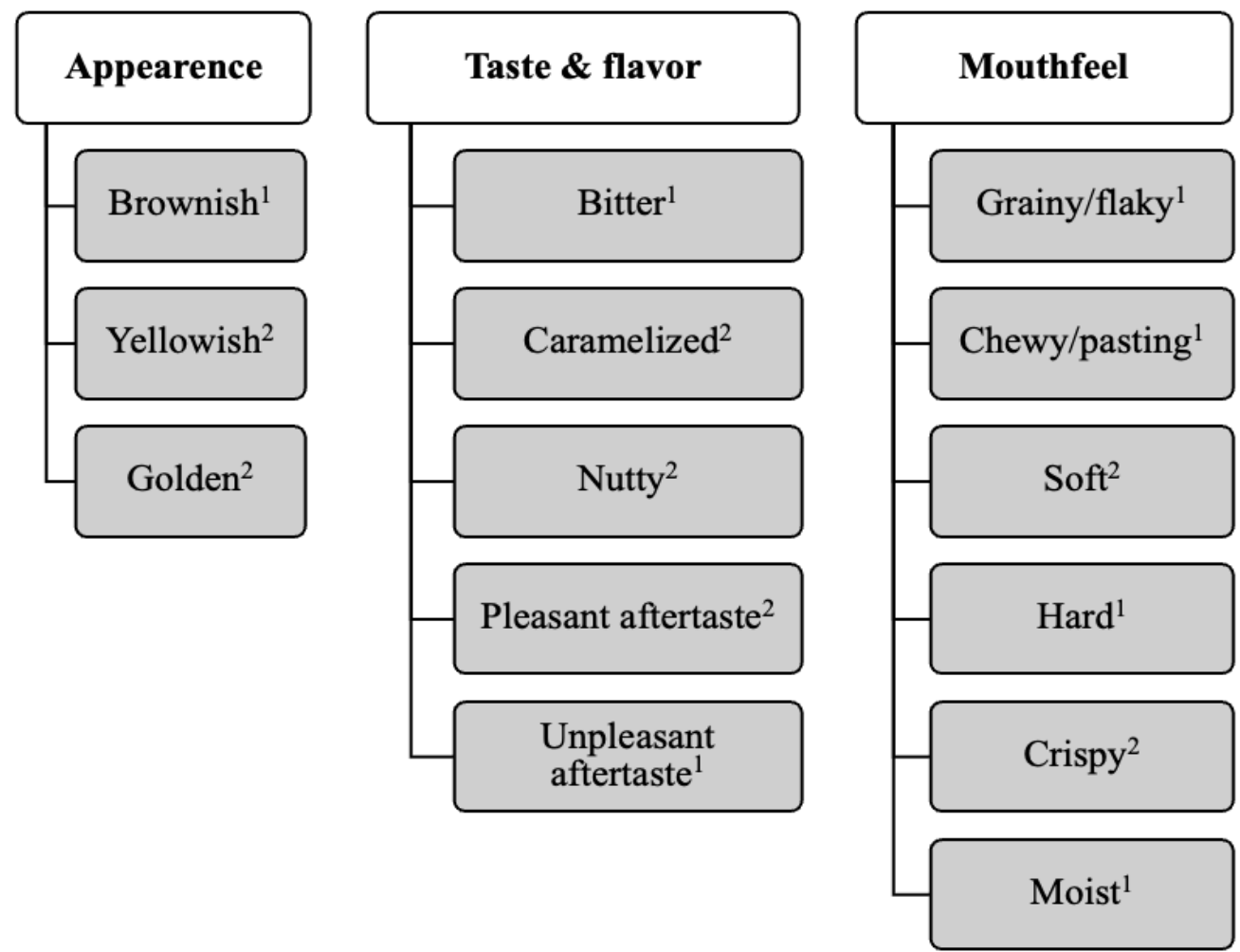

Figure 2. List of selected sensory descriptors used for CATA ballot ( 1 and 2 signifies negative and positive sensory descriptors, respectively)

Assessment of total phenolic content (TPC): To assess the total phenolic content of the nutrition bars with different levels of quercetin, a method reported by Lin et al. [16] was followed. In this method, a methanolic extract of bars was reacted with Folin-Ciocalteau reagent $(0.1 \mathrm{~mL})$ and deionized water $(1.58 \mathrm{~mL})$ for 6

Assessment of antioxidant activity: DPPH free radical scavenging activity: DPPH free radical scavenging activity of the bars was measured by adding different concentrations of extracts to $60 \mu \mathrm{M}$ methanolic solution of DPPH and recording the absorbance at $517 \mathrm{~nm}$. $\mathrm{IC}_{50}$ value was determined from the plotted graph of min and then mixed with $2 \mathrm{M}$ sodium carbonate 0.3 $\mathrm{mL}$ ). The mixture was then stirred and incubated for $2 \mathrm{~h}$ and the absorbance was recorded in a spectrophotometer at $765 \mathrm{~nm}$. The values were expressed as gallic acid equivalents per $100 \mathrm{~g}$ nutrition bar dry matter.

scavenging activity against the different concentrations of extracts, which is defined as the total antioxidant necessary to decrease the initial DPPH radical concentration by $50 \%$. The measurements were done in triplicates and their scavenging effects were calculated based on the percentage of DPPH scavenged. The 
antioxidant activity was expressed as Trolox equivalent (mg Trolox/100g extract) which served as a positive control.

Statistical analysis: All experiments were done in duplicate and the measurements were performed in triplicates and presented as mean \pm standard deviation. Statistical significance of the results obtained from each set of experiments and the score of all the sensory attributes were analyzed using one-way analysis of variance (ANOVA) followed by Tukey's test using Minitab 19.0 software. Statistical significance was set at $p<0.05$. Apart from this, Wilcoxon signed rank test was applied to evaluate the overall favourability and willingness to buy (FACT scale). Correspondence Analysis (CA) was applied to identify significant correlation between sensory attributes and CATA ballot descriptors.

\section{RESULTS AND DISCUSSIONS}

Sensory evaluation and profiling: Sensory evaluation and profiling of quercetin-based nutrition bars was done to choose the best suitable concentration of quercetin to be added to the nutrition bars, so that the bars would test either comparable to or better than the control nutrition bar samples. Therefore, in order to achieve unbiased results, a sensory panel was constituted based on participants' frequency of consuming nutrition bars. Based on the pre-test questionnaires, it was revealed that out of a total of 30 selected sensory panelists, 18 consumed cereal bars "quite frequently" and the remaining 12 consumed "once a week". Since, quercetin-based nutrition bars are a first of its kind, thus, it was important to evaluate its acceptance based on a consumer's willingness to buy. Therefore, following the consumption frequency, nutrition bars were evaluated for its overall favorability and consumer's willingness to buy based on the FACT scale. As shown in
Figure 3, the nutrition bar samples were divided into two homogenous groups ( $a$ and $b$ ), stating that similar to the control samples (overall favorability= $4.5 \pm 0.3$; $\mathrm{FACT}=4.5 \pm 0.4)$, nutrition bar samples with a quercetin concentration of 20,40 and $60 \mathrm{mg}$ were judged as the most acceptable by the sensory panelists. The lowest acceptability was found for the nutrition bar sample with $80 \mathrm{mg}$ quercetin content (overall liking= 2.5 \pm 0.3 ; $F A C T=2.0 \pm 0.5)$. This may be due to an unappealing appearance, including a dry and flaky texture, a slight bitter taste and an unacceptable mouthfeel, which were observed for this sample due to higher concentrations of quercetin powder.

Once the consumer acceptability was established, sensory profiling was done using CATA analysis to understand the differences between the nutrition bar samples. The 14 sensory descriptors that were used by the sensory panellists to describe the nutrition bar samples were divided into seven positive (yellowish, golden, caramelized, nutty, pleasant aftertaste, soft and crispy) and seven negative (brownish, bitter, unpleasant aftertaste, grainy/flaky, chewy/pasting, hard and moist) attributes. According to the results by the correspondence analysis of CATA frequencies (Figure 4), for these positive and negative attributes, a similarity in sensory descriptors was observed for control and B20 samples, while E-80 samples were found to be dissimilar due to its negative descriptors. In terms of acceptability, C-40 and D-60 samples were found to have the maximum frequency of positive descriptors. These results suggested that addition of quercetin content higher than $60 \mathrm{mg}$ had a negative impact on the sensory quality of nutrition bars. It was also established that addition of quercetin content in the range of 40 to $60 \mathrm{mg}$ not only had a positive impact on the acceptability of nutrition bars, but also improved its sensory quality as compared to the control samples. 


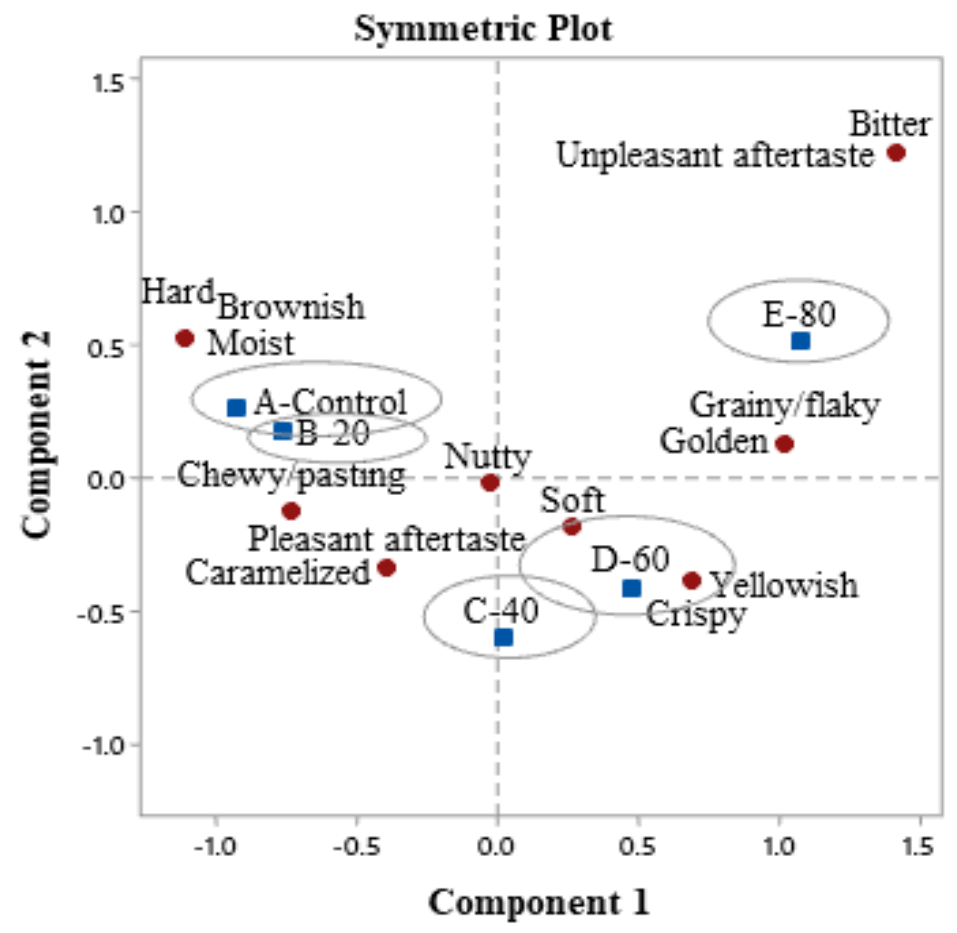

Figure 3. Evaluation of overall liking and willingness to buy (FACT scale) for quercetin-based nutrition bar samples according to Wilcoxon test applied to each variable ( $95 \%$ confidence); (,$b=$ homogenous groups)

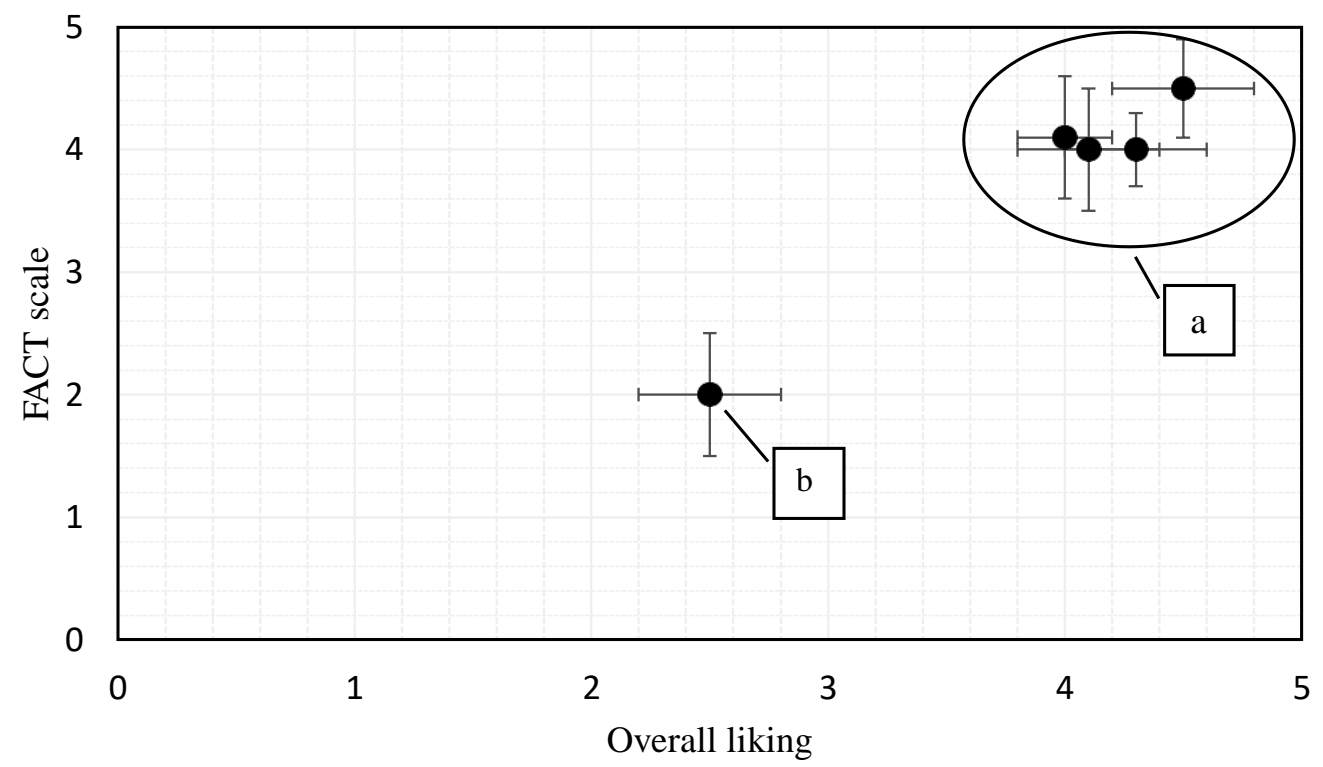

Figure 4. Correspondence analysis (CA) of CATA frequencies of significant appearance, taste and flavor and mouthfeel attributes of quercetin-based nutrition bar samples, with overlap of $95 \%$ confidence ellipses

Effect of varying levels of quercetin on water activity:

Water activity is one of the most crucial intrinsic parameters that govern food quality, stability and shelf life. A water activity of $0.450-0.570$ was reported as most suitable for a cereal-based bar by Sharon et al. [17]. Water activity of nutrition bars, developed in this 
study, gathered values between $0.41-0.66$ (Table 2).

These values were in range with other antioxidant rich cereal bars containing quinoa (0.33-0.7) [18] and acerola residue flours $(<6.5)$ [19]. Also, a significant decrease in the water activity of formulated nutrition bars was observed with increasing levels of quercetin. Owing to a decline in the values, it may be anticipated that low water activity should favor the shelf stability of the product. However, such a product may still be rejected by consumers because of its appearance, taste or smell. Thus, sensory evaluation remains the prime criteria for determining the overall acceptance of the bars.

Table 2. Water activity, texture and color attributes of nutrition bars with different levels of quercetin

\begin{tabular}{|c|c|c|c|c|c|c|c|c|c|}
\hline \multirow{2}{*}{$\begin{array}{c}\text { Nutrition } \\
\text { bar } \\
\text { samples }\end{array}$} & \multirow{2}{*}{$\begin{array}{l}\text { Water } \\
\text { activity } \\
\text { (aw) }\end{array}$} & \multicolumn{5}{|c|}{ Textural properties } & \multicolumn{3}{|c|}{ Color attributes } \\
\hline & & $\begin{array}{c}\text { Hardness } \\
\text { (g) }\end{array}$ & $\begin{array}{c}\text { Springiness } \\
(\mathrm{mm})\end{array}$ & $\begin{array}{c}\text { Cohesiveness } \\
\text { (g) }\end{array}$ & Resilience & Chewiness & $L^{*}$ & $a^{*}$ & $b^{*}$ \\
\hline A-Control & $\begin{array}{l}0.66 \pm \\
0.08^{a}\end{array}$ & $\begin{array}{c}970.33 \pm \\
35.98^{d}\end{array}$ & $\begin{array}{l}0.69 \pm \\
0.07^{a}\end{array}$ & $\begin{array}{l}0.56 \pm \\
0.04^{a}\end{array}$ & $\begin{array}{c}891.33 \pm \\
9.86^{a}\end{array}$ & $\begin{array}{c}398.75 \pm \\
9.36^{\mathrm{a}}\end{array}$ & $\begin{array}{c}45.34 \pm \\
2.30^{\mathrm{e}}\end{array}$ & $\begin{array}{l}7.59 \pm \\
1.23^{\mathrm{a}}\end{array}$ & $\begin{array}{r}29.78 \pm \\
2.95^{e}\end{array}$ \\
\hline B-20 & $\begin{array}{l}0.52 \pm \\
0.07^{b}\end{array}$ & $\begin{array}{c}1101.42 \pm \\
22.63^{c}\end{array}$ & $\begin{array}{l}0.44 \pm \\
0.03^{b}\end{array}$ & $\begin{array}{l}0.41 \pm \\
0.02^{b}\end{array}$ & $\begin{array}{c}886.89 \pm \\
12.22^{\mathrm{a}}\end{array}$ & $\begin{array}{c}221.23 \pm \\
8.45^{b}\end{array}$ & $\begin{array}{c}48.66 \pm \\
3.33^{d}\end{array}$ & $\begin{array}{l}5.99 \pm \\
2.22^{\mathrm{b}}\end{array}$ & $\begin{array}{r}32.07 \pm \\
3.47^{d}\end{array}$ \\
\hline C-40 & $\begin{array}{l}0.48 \pm \\
0.04^{c}\end{array}$ & $\begin{array}{c}1225.21 \pm \\
40.33^{b}\end{array}$ & $\begin{array}{l}0.47 \pm \\
0.03^{b}\end{array}$ & $\begin{array}{l}0.39 \pm \\
0.05^{b}\end{array}$ & $\begin{array}{c}835.20 \pm \\
10.99^{b}\end{array}$ & $\begin{array}{c}225.86 \pm \\
9.78^{b}\end{array}$ & $\begin{array}{c}52.90 \pm \\
1.98^{c}\end{array}$ & $\begin{array}{l}4.43 \pm \\
2.76^{c}\end{array}$ & $\begin{array}{r}34.99 \pm \\
1.89^{c}\end{array}$ \\
\hline D-60 & $\begin{array}{l}0.46 \pm \\
0.06^{d}\end{array}$ & $\begin{array}{c}1299.87 \pm \\
47.57^{b}\end{array}$ & $\begin{array}{l}0.48 \pm \\
0.03^{b}\end{array}$ & $\begin{array}{l}0.35 \pm \\
0.03^{b}\end{array}$ & $\begin{array}{c}826.56 \pm \\
11.11^{b}\end{array}$ & $\begin{array}{c}301.15 \pm \\
11.54^{b}\end{array}$ & $\begin{array}{l}55.34 \pm \\
3.45^{b}\end{array}$ & $\begin{array}{l}3.96 \pm \\
2.10^{d}\end{array}$ & $\begin{array}{c}36.20 \pm \\
2.45^{b}\end{array}$ \\
\hline$E-80$ & $\begin{array}{l}0.41 \pm \\
0.07^{e}\end{array}$ & $\begin{array}{c}1345.21 \pm \\
21.20^{\mathrm{a}}\end{array}$ & $\begin{array}{l}0.50 \pm \\
0.04^{b}\end{array}$ & $\begin{array}{l}0.34 \pm \\
0.04^{b}\end{array}$ & $\begin{array}{c}811.35 \pm \\
6.32^{c}\end{array}$ & $\begin{array}{c}321.57 \pm \\
5.67^{c}\end{array}$ & $\begin{array}{c}59.02 \pm \\
3.90^{\mathrm{a}}\end{array}$ & $\begin{array}{l}2.98 \pm \\
1.90^{d}\end{array}$ & $\begin{array}{c}38.64 \pm \\
3.76^{\mathrm{a}}\end{array}$ \\
\hline
\end{tabular}

*Means followed by different letters in each column are significantly different $(p \leq 0.05)$.

Effect of varying levels of quercetin on texture and color attributes: Physical as well as chemical interactions between the ingredients in cereal bars during processing usually influence the taste and texture of the cereal bars. The texture of the product is an important parameter that not only determines the overall acceptability but also impact its shelf life. Table 2 reports the values of hardness, springiness, resilience, chewiness and cohesiveness as a measure of texture of the nutrition bars. Quercetin addition significantly ( $p$ $<0.05)$ increases hardness of the nutrition bars in comparison to the control. However, the increase does not imply rejection by consumers. Correlating the results with low water activity and sensory evaluation, consumer panel preferred the bars formulated with a higher concentration of quercetin owing to their crispiness. Unlike hardness, the differences in cohesiveness, springiness, resilience and chewiness of the bar formulations were found to be non-significant ( $p$ $>0.05)$.

Color is an equally important aspect of nutrition bars which attracts the consumer and define their purchase intention. The effect of quercetin concentration on color of the formulated nutrition bars in terms of $L^{*}, a^{*}$ and $B^{*}$ is reported in Table 2. $L^{*}$ parameter signifies lightness of the product, and the bars had intermediate values, ranging between 45.34 and 51.02. Dark color of the product diminished with increasing concentration of quercetin in increasing concentration (reduction in $\mathrm{L}^{*}$ and $\mathrm{b}^{*}$ values). Product 
redness, as measured by a* values, gradually decreased, with increased quercetin concentration. Higher $b^{*}$ values indicated greater yellow component in the product color. The cereal bar with $80 \mathrm{mg}$ quercetin (Sample E), was found to have the maximum intense yellow component, clearly owing to the yellow tone of the quercetin powder, and thus obtained appreciable acceptability in terms of color as well as visual appearance during sensory evaluation. Similar results were obtained by Lin and Zhou [20], who reported higher $b *$ value in quercetin-fortified bread crumb as compared to the control bread, because of the accumulation and pre-dominance of yellow colour from quercetin powder. However, our results are in disagreement with Zhang et al. [21], who demonstrated darker color and reduced lightness of quercetinenriched cookies. This could be attributed to the color of other roasted ingredients in the formulated bar or maillard browning products. Khouryieh and Aramouni [22] also reported maillard and caramelization reactions in flaxseed flour incorporated cereal bars, thus revealing a darker color.

Total phenolic content (TPC) and Antioxidant capacity: Daily intake of phenolic antioxidants plays an essential role in reducing the risk of diseases, such as atherosclerosis, cardiovascular disease etc. The consumption of oat-based breakfast cereals has been reported to be a significant contributor to the total polyphenol content and antioxidant potential in the diet [23]. In addition to oats and quinoa, pure quercetin extract was used to formulate bars in this study, which resulted in a high total phenolic content and antioxidant activity in comparison to the control sample. Table 3 shows the values of TPC and antioxidant activity, expressed as mg Gallic acid/ $100 \mathrm{~g}^{-1}$ dry matter and $\mathrm{mg}$ Trolox $100 \mathrm{~g}^{-1}$ dry matter, respectively. With increasing levels of quercetin, total phenolic content in formulated bars showed significant difference among each other.

Table 3. Total phenolic content (TPC) and antioxidant activity of nutrition bars with different levels of quercetin

\begin{tabular}{|c|c|c|}
\hline Nutrition bar samples & TPC (mg Gallic acid/ $100 \mathrm{~g}^{-1}$ dry matter) & DPPH (mg Trolox $100 \mathrm{~g}^{-1}$ dry matter) \\
\hline A-Control & $41.2 \pm 6.1^{e}$ & $22.6 \pm 2.3^{e}$ \\
\hline B-20 & $87.5 \pm 5.8^{d}$ & $32.9 \pm 1.4^{d}$ \\
\hline C-40 & $111.2 \pm 5.5^{c}$ & $65.6 \pm 2.8^{c}$ \\
\hline D-60 & $255.9 \pm 6.6^{b}$ & $93.2 \pm 1.3^{b}$ \\
\hline$E-80$ & $398.7 \pm 5.9^{a}$ & $144.7 \pm 2.0^{\mathrm{a}}$ \\
\hline
\end{tabular}

${ }^{*}$ Means followed by different letters in each column are significantly different $(p \leq 0.05)$.

Comparing the results among formulation types, the highest content of phenolics was found in Sample $E$ (398.7 $\pm 5.9 \mathrm{mg}$ GAE/100 g), followed by Sample D (255.9 $\pm 6.6 \mathrm{mg} \mathrm{GAE} / 100 \mathrm{~g})$ and so on. Furthermore, DPPH radical scavenging activity of the bars ranged between $54.4 \pm 5.3 \mathrm{mg}$ Trolox/100 gm to $609.8 \pm 5.2 \mathrm{mg}$ Trolox/100 gm, and showed a significant increase in antioxidant capacity with increasing quercetin concentration. The high phenolic content may be related to high DPPH radical scavenging activity of the nutrition bar. Results of our study, for total phenolic content and antioxidant capacity were found to be in compliance with Kaur et al [24], who developed an antioxidant rich gluten free cereal-based bar from buckwheat flour which is a good source of phenolics, However, our findings did not corroborate with previous 
reports by Mendes et al [25] who demonstrated low antioxidant potential of cereal bars developed with fruit peels and baru nuts, owing to dehydration and roasting of ingredients. However, quercetin was added to our formulations post heat treatment, and, thus, retained its maximum antioxidant capacity.

\section{CONCLUSION}

Quercetin-based nutrition bars containing oats, quinoa, canola oil and jaggery as key ingredients were incorporated with varying levels of quercetin. Samples without quercetin were used as the experimental control. Addition of quercetin significantly affected the water activity values as well as color attributes of the bars. Total phenolic content as well as antioxidant potential evidently was significantly increased with varying levels of quercetin. As far as texture was concerned, only the hardness values had a significant increase with increasing levels of quercetin, thus, leading to much better product in terms of crispiness. This may be correlated with high sensory acceptance among the consumer panel in terms of visual appearance as well as color. However, use of quercetin in concentrations higher than $60 \mathrm{mg} / 100 \mathrm{~g}$, affected the sensory qualities of the nutrition bars negatively, due to a typical bitter taste of quercetin extract.

List of Abbreviations: USFDA: U.S. Food and Drug Administration, GRAS: generally recognized as safe, RTE: ready-to-eat, FACT: Food Action Rating Scale, CATA (check-all-that-apply), TPC: Total phenolic content.

Competing Interest: The authors have no conflict of interest for this research article.

Authors' Contribution: Uma Bansal designed and performed data, Aastha Bhardwaj and Somnath Singh analyzed data, Sucheta Data wrote curation, Nitya Sharma Data wrote, investigated and validated, Vasudha Bansal visualized, edited, and supervised.

\section{REFERENCES}

1. Bansal V. Sharma A. Ghanshyam C. \& Singla ML: Optimization and characterization of pulsed electric field parameters for extraction of quercetin and ellagic acid in emblica officinalis juice. J Food Measur Characteriz 2014, 8(3), 225-233. https://doi.org/10.1007/s11694-014-9189-0

2. David AVA. Arulmoli $R$ and Parasuraman S: Overviews of biological importance of Quercetin: a Bioactive Flavonoid. Pharmacognosy reviews 2016, 10(20), 84-89. doi: 10.4103/0973-7847.194044

3. Lai WF. and Wong WT: Design and optimization of quercetin-based functional foods. Critical Rev Food Sci Nutri 2021, 1-17.

\section{https://doi.org/10.1080/10408398.2021.1913569}

4. Boots AW. Haenen GR and Bast A: Health effects of quercetin: from antioxidant to nutraceutical. Eur J Pharmacol 2008, 585(2-3), 325-337. https://doi.org/10.1016/i.ejphar.2008.03.008

5. Abdel-Latif MA, Elbestawy AR. El-Far AH. Noreldin AE. Emam M. Baty RS., ... and Hatem S: Quercetin dietary supplementation advances growth performance, gut microbiota, and intestinal mrna expression genes in broiler chickens. Animals 2021, 11(8), 2302.

https://doi.org/10.3390/ani11082302

6. Teibo JO. Ayinde KS. Olaoba OT. Adelusi TI. Teibo TKA. Bamikunle MV. ... and Batiha GES: Functional foods' bioactive components and their chemoprevention mechanism in cervical, breast, and liver cancers: A systematic review. Funct Foods Health Dis. 2021, 11(11), 559-585. DOI: 10.31989/ffhd.v11i11.818

7. Bischoff, S.C. Quercetin: potentials in the prevention and therapy of disease. Current Opinion Clinical Nutrit Metabol Care 2008, 11(6), 733-740. doi: 10.1097/MCO.0b013e32831394b8

8. GRAS Notice Inventory-Agency Response Letter GRAS Notice No. GRN 000341. Available online https://wayback.archiveit.org/7993/20171031012354/http s://www.fda.gov/Food/IngredientsPackagingLabeling/GRAS /Noticelnventory/ucm235935.htm (accessed on 1 April 2019)

9. Cione E. La Torre C. Cannataro R. Caroleo MC. Plastina P and Gallelli L. Quercetin, epigallocatechin gallate, curcumin, and resveratrol: from dietary sources to human microRNA modulation. Molecules 2020, 25(1), p.63. https://doi.org/10.3390/molecules25010063 
10. Kashyap D. Garg VK. Tuli HS. Yerer MB. Sak K. Sharma AK. Kumar M. Aggarwal V and Sandhu SS: Fisetin and Quercetin: promising flavonoids with chemopreventive $\begin{array}{llll}\text { potential. } & \text { Biomol 2019, 9(5), } 174\end{array}$ https://doi.org/10.3390/biom9050174

11. Scheepens A. Tan K and Paxton JW: Improving the oral bioavailability of beneficial polyphenols through designed synergies. Genes and Nutrition, 2010, 5(1), 75-87. https://doi.org/10.1007/s12263-009-0148-z

12. Khaerunnisa S. Kurniawan H. Awaluddin R. Suhartati S and Soetjipto S: Potential inhibitor of COVID-19 main protease (Mpro) from several medicinal plant compounds by molecular docking study. Preprints 2020. pp.1-14, doi: 10.20944/preprints202003.0226.v1

13. Ravindra, M.P. and Sunil, M.D. (2018). Development and Quality Evaluation of Puffed Cereal Bar. International Journal of Pure and Applied Bioscience, 6(5), 930-936.

14. Ribeiro JC. Lima RC. Maia MR. Almeida AA. Fonseca AJ. Cabrita ARJ. \& Cunha LM: Impact of defatting freeze-dried edible crickets (Acheta domesticus and Gryllodes sigillatus) on the nutritive value, overall liking and sensory profile of cereal bars. LWT- Food Sci Technol 2019, 113, 108335. https://doi.org/10.1016/i.lwt.2019.108335

15. AOAC. (2003). Official methods of analysis of AOAC International, 17th edn., revision 2, Vol II (Horwitz, W., Ed). Association of Official Analytical Chemists (AOAC) International, Gaithersburg, MD.

16. Lin J. Tan YXG. Leong LP and Zhou W: Steamed bread enriched with quercetin as an antiglycative food product: Its quality attributes and antioxidant properties. Food \& Function 2018, 9(6), 3398-3407. https://doi.org/10.1039/C8FO00818C

17. Sharon RB. Brander RW and Coleman EC: Cereal Bar and Method of their Manufacture. Krafts Foods Holdings Inc. 2009.

18. Padmashree A. Negi N. Haridas S. Govindaraj T. Kumar KRA. Semwal AD and Sharma GK: Development and Quality Evaluation of Choco Quinoa Nutri Bar during Storage. Food $\begin{array}{llll}\text { Nutri Sci } & \text { 2018, }\end{array}$ DOI: $\underline{10.4236 / f n s .2018 .97067}$

19. Marques TR. Corrêa AD. de Carvalho Alves AP. Simão AA. Pinheiro ACM and de Oliveira Ramos V: Cereal bars enriched with antioxidant substances and rich in fiber, prepared with flours of acerola residues. J Food Sci Technol
2015, 52(8), 5084-5092. https://doi.org/10.1007/s13197014-1585-2

20. Lin J and Zhou W: Role of Quercetin in the physicochemical properties, antioxidant and antiglycation activities of bread. Journal of Functional Foods 2018, 40, 299-306. https://doi.org/10.1016/j.jff.2017.11.018

21. Zhang $\mathrm{X}$. Chen $\mathrm{F}$ and Wang $\mathrm{M}$. Antioxidant and antiglycation activity of selected dietary polyphenols in a cookie model. Journal of Agricultural and Food Chemistry 2014, 62(7), 1643-1648. https://doi.org/10.1021/jf4045827

22. Khouryieh $\mathrm{H}$ and Aramouni F: Effect of flaxseed flour incorporation on the physical properties and consumer acceptability of cereal bars. Food Sci Technol Int. 2012, 19, $549-556$

23. Ryan L. Thondre PS and Henry CJK: Oat-based breakfast cereals are a rich source of polyphenols and high in antioxidant potential. J Food Comp. Anal., 2011, 24(7), 929934. https://doi.org/10.1016/j.jfca.2011.02.002

24. Kaur R. Ahluwalia, P. Sachdev PA and Kaur A: Development of gluten-free cereal bar for gluten intolerant population by using quinoa as major ingredient. J. Food Sci. Technol. 2018, 55(9), 3584-3591. https://doi.org/10.1007/s13197$\underline{018-3284-x}$

25. Mendes NDSR. Gomes-Ruffi CR. Lage ME. Becker FS. Melo AAMD. Silva FAD and Damiani C: Oxidative stability of cereal bars made with fruit peels and baru nuts packaged in different types of packaging. Food Sci Technol 2013, 33(4), 730-736. 